\title{
O desenvolvimento do turismo pedagógico em áreas rurais: o caso do Projeto Viva Ciranda, Joinville (SC)
}

\section{The development of educational tourism in rural areas: the case of Viva Ciranda Project, Joinville (SC, Brazil)}

\author{
Thaise Costa Guzzatti, Vinicius Boneli Vieira, Vanessa Cistina Venzke Falk, \\ Valério Alécio Turnes
}

\section{RESUMO}

O presente artigo aborda o desenvolvimento do turismo pedagógico em propriedades rurais de Joinville (SC), no âmbito do projeto Viva Ciranda. O turismo pedagógico pode também ser considerado como uma atividade de educação ambiental, cujo objetivo é demonstrar na prática o conteúdo apresentado em sala de aula. Em geral, as atividades acontecem ao ar livre, em meio à natureza e ao campo. Nas atividades os alunos têm a oportunidade de vivenciar o cotidiano da comunidade local e adquirir novos conhecimentos e informações sobre o espaço rural, interagindo com agricultores e proprietários rurais. Trata-se também de uma possibilidade de oferta de serviços turísticos em estadias curtas e com agendamento prévio, fator que contribui para a organização da família rural no desenvolvimento de suas atividades agropecuárias cotidianas. O contexto para o desenvolvimento do programa de turismo pedagógico em Joinville era bastante positivo, visto que a cidade apresentava em 2009, 129.876 alunos distribuídos na educação infantil, ensino fundamental, educação de jovens e adultos e ensino médio regular profissionalizante. Outro fator interessante foi a proximidade das propriedades rurais ao centro da cidade, sendo que a distância média era de aproximadamente $15 \mathrm{Km}$. O baixo investimento que a atividade demanda por parte dos proprietários para a sua implementação também foi um fator de motivação para a adesão dos agricultores a proposta. Para o desenvolvimento do projeto, uma série de ações foram desenvolvidas, tais como a seleção e diagnóstico das propriedades; consultoria pedagógica; assistência técnica aos proprietários para implementação das atividades por uma equipe multidisciplinar formada por bacharéis em turismo, agrônoma e pedagoga; realização de visitas teste e posterior adequações das atividades desenvolvidas; ações promocionais, entre outros. O projeto envolve atualmente 13 proprietários rurais de cinco localidades diferentes de Joinville. Em 2010 mais de 2.500 alunos visitaram as propriedades rurais, gerando trabalho, renda e promovendo o resgate da autoestima dos agricultores envolvidos.

PALAVRAS-CHAVE: Turismo Pedagógico; Agricultura Familiar; Viva Ciranda. 


\section{ABSTRACT}

This article discusses the development of the educational tourism sector in private properties in the rural areas of Joinville, State of Santa Catarina, under the Viva Ciranda Project. Educational tourism can be considered an activity of environmental education, with the objective of putting into practice what has been learned in the classroom. In general, the activities are conducted outdoors, in contact with nature. The students have the opportunity to experience the daily life of the local community and learn about the rural area, interacting with the farmers and landowners. It can also offer tourism services to visitors. These can include shortterm accommodation and pre-booked visits to rural properties, allowing the rural families to arrange their daily routine appropriately. There are various factors that have contributed positively to the success of the educational tourism programme development in Joinville such as; in 2009 a total of 129,876 students from state run nurseries and schools for infants, youngsters and adults, as well as technical vocational schools. Another interesting factor was the proximity between the city centre and the rural properties, with an average distance of $15 \mathrm{~km}$. The low investment necessary for the activity implementation was another factor of motivation for the farmers and landowners to join the project. A number of actions have been implemented for the project's development, such as the selection and evaluation of the properties; educational consultation; technical assistance to the farmers and landowners for the activity implementation. This was offered by a multidisciplinary team consisting of tourism graduates, an agronomist and a teacher; carrying out of test-visits to the properties and subsequent adaptations of the activities; marketing actions, among others. Currently the project counts with 13 farmers and/or landowners from 5 different rural areas of Joinville. In 2010 more than 2,500 students visited the rural properties, creating jobs, income and resulting in the recovery of the farmers' and landowners' self-esteem.

KEYWORS: Educational Tourism; Family Farming; Viva Ciranda Project.

\section{Introdução}

Estudos da FAO/INCRA de 1994 apontam para a existência de dois tipos de agricultura no Brasil: a familiar e a patronal. As principais características que as diferenciam, segundo estes estudos, são: agricultura patronal - acontece a total separação dos fatores gestão e trabalho, a organização do processo produtivo é centralizada; a ênfase do processo produtivo está na especialização e em práticas agrícolas padronizáveis; o predomínio do trabalho empregado é assalariado; adota-se o uso de tecnologias direcionadas à eliminação das decisões "de terreno" e "de momento"; as tecnologias empregadas buscam principalmente a redução das necessidade de mão de obra e a ênfase está no uso de insumos comprados.

Em contrapartida, o modelo de agricultura familiar prevê o íntimo relacionamento entre a gestão e o trabalho; o processo produtivo é dirigido diretamente pelo agricultor; a ênfase do processo produtivo está na diversificação da produção; tem-se a ênfase na durabilidade dos recursos naturais e na qualidade de vida; o trabalho assalariado é apenas complementar; as decisões são imediatas, adequadas ao alto grau de imprevisibilidade do processo produtivo; as decisões são tomadas in loco, condicionadas pelas especificidades do processo produtivo e dá-se ênfase no uso de insumos internos. 
O Brasil, assim como a maioria dos países do mundo, adotou uma política de incentivo e privilégio ao modelo patronal. Isso teve como justificativa, a necessidade do aumento das exportações brasileiras e a contribuição, desta forma, ao equilíbrio do balanço de pagamentos, papel que a agricultura foi chamada a desempenhar para garantir a articulação das economias reflexas na divisão social do trabalho criado pelo sistema capitalista na sua fase de desenvolvimento monopolista (SILVA, 1982).

As estratégias estabelecidas, principalmente pelo Governo Brasileiro, para o aumento da produção agrícola a partir da década de 1960, foram marcadas pelo processo que ficou conhecido como Revolução Verde. Este processo centrou-se na substituição do trabalho braçal e das técnicas produtivas tradicionais por "modernas" tecnologias demandadoras de energia, de insumos químicos e capital. Para Goodman et al., (1990) os altos rendimentos das variedades de culturas positivamente sensíveis ao uso de fertilizantes constituem a inovação central da Revolução Verde, principal veículo de transformação da agricultura do Terceiro Mundo por parte dos capitais agroindustriais multinacionais.

Pesquisadores como Navarro (2001), Abramoway (1998) e Veiga (1991; 2002) fazem fortes críticas ao avanço do modelo de desenvolvimento pautado na Revolução Verde, no consumo de combustível fóssil e baseado em macroplanos e na grande propriedade da terra, apontando para severas limitações deste modelo, especialmente em termos socioambientais.

Guzzatti corrobora, ao afirmar que

(...) a modernização a que foi submetida a agricultura brasileira resultou (e ainda resulta) no acúmulo de capital por parte das grandes empresas integradoras e dos grandes proprietários rurais; ocasionou (e ocasiona) prejuízos ambientais; provocou (e provoca) a contaminação dos alimentos (com prejuízos para a saúde de quem produz e de quem consome) e, principalmente, levou (e leva) ao empobrecimento e à exclusão social pessoas que historicamente foram responsáveis pela alimentação da população brasileira (GUZZATTI, 2010, p.55).

José Eli da Veiga (1996) faz parte do grupo de autores que defende que a agricultura familiar deve ser priorizada pelas políticas públicas. Para o autor,

sob o prisma da sustentabilidade (estabilidade, resiliência e eqüidade), são muitas as vantagens apresentadas pela organização familiar na produção agropecuária, devido à sua ênfase na diversificação e na maleabilidade de seu processo decisório. A versatilidade da agricultura familiar se opõe à especialização cada vez mais fragmentada da agricultura patronal (VEIGA, 1996, p.395). 
Os dados do censo agropecuário realizado em 2006 mostram a importância da agricultura familiar no Brasil e ajudam a justificar a necessidade de ações adequadas para a sua manutenção e o seu fortalecimento. Dos 5.175.489 estabelecimentos rurais existentes no País, $84 \%$, ou seja, 4.367 .902 estabelecimentos eram classificados como familiares e ocupavam $24 \%$ da área de terras (80.250.453 hectares de um total de 329.941.393 hectares).

Por outro lado, a tabela a seguir mostra a relação de pessoal ocupado na agricultura familiar, em comparação com a agricultura patronal, por estabelecimento rural, em 2006, no Brasil (Tabela 1).

Tabela 1: pessoal ocupado no estabelecimento em 31.12, por sexo, segundo a agricultura familiar (BRASIL, 2006).

Table 1: persons employed in the establishment in 31.12, by sex, according to family farming (BRAZIL, 2006).

\begin{tabular}{|c|c|c|c|c|c|c|}
\hline \multirow{4}{*}{$\begin{array}{l}\text { Agricultura } \\
\text { familiar }\end{array}$} & \multicolumn{6}{|c|}{ Pessoal ocupado (1) no estabelecimento em 31.12 .06} \\
\hline & \multirow{2}{*}{\multicolumn{2}{|c|}{ Total }} & \multicolumn{4}{|c|}{ Sexo } \\
\hline & & & \multicolumn{2}{|c|}{ Homens } & \multicolumn{2}{|c|}{ Mulheres } \\
\hline & Total & $\begin{array}{c}\text { De } 14 \\
\text { anos e } \\
\text { mais }\end{array}$ & Total & $\begin{array}{c}\text { De } 14 \\
\text { anos e } \\
\text { mais }\end{array}$ & Total & $\begin{array}{c}\text { De } 14 \\
\text { anos e } \\
\text { mais }\end{array}$ \\
\hline Total & 16.567 .544 & 15.505 .243 & 11.515.194 & 10.919.257 & 5.052 .350 & 4.585 .986 \\
\hline $\begin{array}{c}\begin{array}{c}\text { Agricultura } \\
\text { familiar }\end{array} \\
\text { Lei 11. } 326\end{array}$ & 12.322 .225 & 11.412 .590 & 8.174 .002 & 7.666 .373 & 4.148 .223 & 3.746 .217 \\
\hline Não familiar & 4.245.319 & 4.092 .653 & 3.341 .192 & 3.252 .884 & 904.127 & 839.769 \\
\hline
\end{tabular}

Fonte: IBGE, Censo Agropecuário, 2006. (1), inclusive produtor.

Source: IBGE, Census of Agriculture, 2006. (1), including producer.

Pode-se perceber que das 15.505 .243 pessoas ocupadas com 14 anos e mais no Brasil, em 2006, mais de 48\% estavam situadas em unidades familiares de produção (IBGE, 2006).

Outra informação relevante diz respeito à produção de alimentos, onde a agricultura familiar aparece como responsável pela produção de $69,76 \%$ do feijão $(\mathrm{Kg})$ produzido no Brasil; $86,70 \%$ da mandioca $(\mathrm{Kg})$; 45,90\% do milho (grão); 58,14\% do leite (litro); 50,01\% das aves (cabeças); $15,95 \%$ dos ovos (dz) e 59,04\% dos suínos (cabeças) (IBGE, 2006).

A criação do Programa Nacional de Fortalecimento da Agricultura Familiar (PRONAF), em 1996, constituiu-se em um marco histórico de reconhecimento da importância deste segmento na produção de alimentos e na geração de emprego e renda para o Brasil. 
Podemos dizer que esta conquista é fruto da movimentação de organizações ligadas aos trabalhadores rurais $e$ aos "pequenos agricultores", somada aos problemas que enfrentava o modelo da "agricultura patronal". Além disso, o processo massivo de urbanização que levou milhares de pessoas para as grandes cidades limitou as opções de emprego neste meio, colocando muitas pessoas em condições subhumanas de vida.

Neste contexto é que a agricultura familiar passa a ser valorizada dentro dos processos que buscam atingir 0 desenvolvimento rural sustentável. Percebe-se o potencial deste segmento em gerar emprego, renda, preservar o meio ambiente, produzir alimentos diferenciados (ênfase na produção de alimentos orgânicos/agroecológicos), preservar a cultura local, etc.; ou seja: políticos e estudiosos passam a se dar conta de que a agricultura familiar apresenta as condições necessárias para manter o meio rural vivo e dinâmico, sendo capaz de manter sua população e atrair outras pessoas.

Outro fator que afeta o desenvolvimento da agricultura familiar no país é, certamente, a questão do consumo. O consumidor, quando faz sua opção de compra, quando escolhe um determinado produto está, mesmo que inconscientemente, contribuindo para a construção de um determinado tipo de sociedade.

Como é citado por Guerra (2008), se nos comportássemos eticamente e responsavelmente cada vez que consumimos, seguramente esta mensagem chegaria aos agentes produtivos e estes começariam a mudar as coisas. Para o autor, cada vez que decidimos o que comprar, onde comprar, quando comprar e em quais circunstâncias o fazemos, estamos sendo verdadeiros decisores sobre qual modelo de desenvolvimento e que economia estamos contribuindo para consumir.

Esta discussão está inserida nos debates sobre economia solidária, que é considerada pelo MTE (2005) como sendo

o conjunto das atividades econômicas - de produção, distribuição, consumo, poupança e crédito - organizadas sob a forma de autogestão, isto é, pela propriedade coletiva dos meios de produção de bens ou prestação de serviços e pela participação democrática (uma cabeço, um voto) nas decisões dos membros da organização ou empreendimento (MTE, 2005, p.7).

O programa da economia solidária se fundamenta na tese de que as contradições do capitalismo criam oportunidades de desenvolvimento de organizações econômicas cuja lógica é oposta à do modo de produção dominante (SINGER, 2002, p.112).

Pode-se fazer uma associação, desta reflexão feita por Singer, com a agricultura familiar e a infinidade de cooperativas, associações, grupos de produção, dentre outros, que se organizaram de forma solidária ao longo dos anos em busca de melhores condições de vida. 
Mance (1999), ao discutir os conceitos fundamentais da colaboração solidária, destaca a questão do consumo solidário, o qual é definido como

O consumo solidário ocorre quando a seleção do que consumimos e feita não apenas considerando o nosso bemviver pessoal, mas igualmente o bem-viver coletivo. Este tipo de conduta somente se torna possível quando as pessoas compreendem que a produção encontra a sua finalidade - ou o seu acabamento - no consumo e que ele tem impacto sobre todo o ecossistema e sobre a sociedade em geral. Em outras palavras, o consumo é a última etapa de um processo produtivo e as escolhas de consumo feitas pelos indivíduos em particular e pela sociedade como um todo - podem influenciar tanto na geração como na manutenção de postos produtivos em uma dada sociedade, na preservação dos ecossistemas, na reciclagem de materiais, no combate à poluição, na promoção do bemestar coletivo da população de sua comunidade, de seu país e do planeta, quando podem, também, gerar desemprego, colaborar na destruição dos ecossistemas e na extinção de espécies vegetais e animais, na produção cada vez maior de lixo não biodegradável, no aumento da poluição e na piora da qualidade de vida das populações de sua comunidade, de seu país e do planeta como um todo (MANCE, 1999, p.29).

Falar em consumo sustentável (ou consciente) requer, necessariamente, abordar o tema da educação. É neste contexto, aliado a necessidade de geração de trabalho e renda aos agricultores familiares, que surge e se justifica o desenvolvimento do turismo pedagógico no espaço rural.

A função pedagógica e educativa do turismo pode estar presente nos diferentes segmentos definidos pelo Ministério do Turismo e também constituir-se como segmento específico. A segmentação da atividade turística ocorre para fins de planejamento, gestão e mercado, sendo definida pelo conjunto de elementos que constituem cada segmento, compondo a oferta de produtos e serviços, além de definir as características e variáveis da demanda.

Segundo o Ministério do Turismo (2006),

[...] a partir da oferta, a segmentação define tipos de turismo (ecoturismo, turismo rural, turismo de aventura, turismo cultural, turismo de pesca, etc.) cuja identidade pode ser conferida pela existência, em um território, de atividades, práticas e tradições (agropecuária, pesca, esporte, manifestações culturais, manifestações de fé); aspectos e características (geográficas, históricas, arquitetônicas, urbanísticas, sociais) e determinados serviços e infraestrutura (de saúde, de educação, de eventos, de hospedagem, de lazer). Com enfoque na demanda, a 
segmentação é definida pela identificação de certos grupos de consumidores caracterizados a partir das suas especificidades em relação a alguns fatores que determinam suas decisões, preferências e motivações, ou seja, a partir das características e das variáveis da demanda (MINISTÉRIO DO TURISMO, 2006, p.03).

Dentre os segmentos trabalhados pelo Ministério do Turismo, está o de turismo de estudos e intercâmbio, o qual é definido como:

Turismo de estudos e intercâmbio constitui-se da movimentação turística gerada por atividades e programas de aprendizagem e vivências para fins de qualificação, ampliação de conhecimento e de desenvolvimento pessoal e profissional (MINISTÉRIO DO TURISMO, 2008, p.15).

No caso do segmento do Turismo Rural, segundo o Ministério do Turismo, Brasil (2010), existem outras terminologias utilizadas na Brasil para se referirem ao turismo rural ou ao turismo no espaço rural, como: turismo na natureza, turismo de interior, alternativo, verde, campestre, sertanejo, agroecoturismo, ecoagroturismo, agroecológico, dentre outras.

Neste trabalho, cujo foco de discussão é a atividade de turismo pedagógico junto à agricultura familiar, adota-se o conceito de agroturismo. Ele é considerado por Guzzatti como

\begin{abstract}
um segmento do turismo desenvolvido no espaço rural por agricultores familiares organizados, dispostos a compartilhar seu modo de vida, patrimônio cultural e natural, mantendo suas atividades econômicas, oferecendo produtos e serviços de qualidade, valorizando e respeitando o ambiente e a cultura local e proporcionando bem estar aos envolvidos (GUZZATTI, 2003, p.53).
\end{abstract}

Este conceito demarca que a atividade de turismo se processa no espaço rural por agricultores familiares ativos nas atividades agropecuárias e pressupõe o intercâmbio com o visitante.

Dentro do vasto cardápio de oferta de serviços disponíveis aos agricultores familiares que trabalham com o agroturismo (alimentação, hospedagem, venda de produtos, lazer e outros) está o turismo pedagógico. A propriedade rural passa a ter, nesta perspectiva, como um de seus objetivos o recebimento de grupos de visitantes dentro do quadro de suas atividades escolares ou extraescolares.

Neste contexto, o turismo pedagógico é compreendido como o conjunto de atividades voltadas ao complemento do ensino escolar e ao estímulo as novas descobertas sobre o meio rural, sua vida, seu patrimônio (histórico, cultural, material, imaterial) etc.

Esta atividade encontra espaço para se desenvolver devido, principalmente, aos seguintes fatores: 
- possibilidade da oferta de serviços turísticos em estadias curtas e com agendamento prévio, fator que contribui para a organização da família rural no desenvolvimento de suas atividades agropecuárias cotidianas;

- evolução dos valores sociais no sentido da importância do conhecimento do meio ambiente e do patrimônio (natural, construído, cultural e paisagístico);

- necessidade de complementação do processo de ensinoaprendizagem com a vivência, possibilitando que o visitante desperte todos os seus sentidos.

O turismo pedagógico pode ser considerado também como uma prática de educação ambiental, cujo objetivo é demonstrar na prática o conteúdo apresentado em sala de aula. Em geral as atividades acontecem ao ar livre, em meio à natureza e ao campo. Nas atividades os alunos têm a oportunidade de vivenciar o cotidiano da comunidade local e adquirir novos conhecimentos e informações sobre o espaço rural, interagindo com agricultores e proprietários rurais.

Vinha (2005), ao abordar os objetivos no desenvolvimento do turismo pedagógico destaca que

o que se pretende com essas atividades é a organização de situações de aprendizagens, relacionadas a conteúdos curriculares, a valores éticos e estéticos, além de atitudes formativas, tais como o desenvolvimento da capacidade de iniciativa e solidificação de amizades; respeito ao outro e fortalecimento da noção de pertencimento a um grupo ou a um ecossistema; experiência de autonomia; elaboração conjunta de regras de convivência, dentre outras (2005, p. 6-7).

No caso específico do turismo pedagógico em áreas rurais, agregase a estes objetivos o desejo de informar aos visitantes sobre a origem dos alimentos consumidos na cidade, a complexidade do processo produtivo e a questão cultural e ambiental a ele atrelada.

\section{O contexto para a proposição de um projeto de turismo pedagógico em Joinville}

No início de 2009, uma reflexão feita pela Fundação Turística de Joinville sobre a situação do agroturismo na cidade, apontou para um cenário de desânimo por parte dos agricultores familiares envolvidos com a atividade. Dentre os vários problemas levantados pelos proprietários rurais, os principais fatores destacados foram a falta de visitantes, as dificuldades para escoamento da produção, a desarticulação do grupo, o abandono da propriedade por parte dos filhos e a falta de recursos financeiros para a realização de investimentos e melhoria das estruturas de recepção.

Após este diagnóstico inicial, a Fundação Turística elencou 
diferentes possibilidades para iniciar um trabalho de revitalização do turismo rural. Era consenso que estas possibilidades deveriam: a) ser de baixo custo de implantação/viabilização, principalmente por parte dos agricultores, visto que não dispunham de recursos financeiros para investimentos; b) trazer um retorno financeiro rápido, pois os agricultores já estavam sem receber visitantes e este era um dos fatores de desmobilização do grupo; c) fortalecer o trabalho associativo e solidário, visto que havia uma tendência de isolamento no grupo; d) contribuir para a valorização das atividades da agricultura familiar e, consequentemente, para o resgate da autoestima dos agricultores envolvidos, especialmente os jovens.

Dentre as diferentes oportunidades/soluções elencadas, a que pareceu mais oportuna foi a iniciativa do turismo pedagógico, visto que não necessitaria de grandes investimentos nas propriedades rurais e, principalmente, pela facilidade de operacionalização e mercado potencial em Joinville e região.

O cenário para o desenvolvimento da atividade era favorável. Joinville é a maior cidade do estado de Santa Catarina, com 515.250 habitantes em 2010 (IBGE, 2010). A distância média das propriedades integrantes do projeto de turismo rural com o centro da cidade é de $15 \mathrm{~km}$, ou seja, facilmente as escolas poderiam levar seus alunos para aulas no meio rural. Além disso, com relação ao número de alunos, Joinville possuía um total de 129.876 alunos em 2009 (Tabela 2).

Tabela 2: número de alunos matriculados em Joinville.

Table 2: Number of students enrolled in Joinville.

\begin{tabular}{c|c|c|c|c|c|c|c}
\hline Ano & $\begin{array}{c}\text { Rede de } \\
\text { Ensino }\end{array}$ & $\begin{array}{c}\text { Educação } \\
\text { Infantil }\end{array}$ & $\begin{array}{c}\text { Ensino } \\
\text { Fundamental }\end{array}$ & \multicolumn{2}{|c|}{$\begin{array}{c}\text { Educação } \\
\text { de Jovens e } \\
\text { Adultos }\end{array}$} & $\begin{array}{c}\text { Ensino Médio } \\
\text { Regular } \\
\text { Profissionalizante }\end{array}$ & Total \\
\hline \multirow{2}{*}{2009} & Estadual & - & 18.103 & 935 & 2.741 & 17.693 & 39.472 \\
\cline { 2 - 8 } & Municipal & 9.928 & 46.041 & 6.569 & - & - & 62.538 \\
\cline { 2 - 8 } & Particular & 8.704 & 7.832 & 541 & 1.738 & 8.579 & 27.394 \\
\cline { 2 - 8 } & Federal & - & - & - & - & 472 & 472 \\
\cline { 2 - 8 } & Total & 18.632 & 71.976 & 8.045 & 4.479 & 26.744 & 129.876 \\
\hline
\end{tabular}

Fonte: IPPUJ (2011, apud INEP/CENSO ESCOLAR 2009/01).

Source: IPPUJ (2011, cited by INEP/CENSO ESCOLAR 2009/01).

Com relação ao número de escolas, Joinville apresentava em 2009, segundo dados do Ippuj (2011), 378 estabelecimentos de ensino, sendo 1 Federal; 43 estaduais; 147 municipais e 187 particulares. 
Com este contexto, em 2010 a Fundação Turística de Joinville, em parceria com a Associação Eco-rural (entidade que reagrupa os agricultores que trabalham com o agroturismo), a Secretaria Municipal de Educação e contando com apoio financeiro do Ministério do Turismo, através da Coordenação Geral de Projetos de Estruturação do Turismo em Áreas Priorizadas deram início ao Projeto Viva Ciranda.

\section{As etapas do projeto}

Para concretizar a iniciativa, foram realizadas as seguintes ações:

- definição de integrantes do projeto: após a visita em várias propriedades rurais, 6 foram selecionadas para participar do projeto. Dentre os critérios para seleção, os principais foram o interesse em receber crianças; o desenvolvimento de práticas agrícolas e pecuárias com respeito ao meio ambiente nas propriedades rurais; a possibilidade de composição de um circuito pedagógico diversificado e representativo das diferentes atividades agrícolas desenvolvidas no município; a existência das condições mínimas de infraestrutura para o recebimento de grupos, sem a necessidade de realização de novos investimentos;

- consultoria para o desenvolvimento de atividades pedagógicas: cada propriedade recebeu a visita de uma pedagoga que, a partir da atividade principal realizada pela família (produção de mel, cultivo de hortaliças orgânicas, produção de flores, criação de cavalos, etc), propôs o desenvolvimento de atividades lúdicas e pedagógicas. Ao final da visita, a pedagoga preparava um relatório, indicando e detalhando atividades a serem desenvolvidas e sugerindo materiais de apoio que poderiam ser confeccionados para as mesmas. $O$ roteiro pedagógico de cada propriedade rural previa um momento inicial de apresentação, o desenvolvimento das atividades lúdicas e pedagógicas definidas para a propriedade e uma atividade final de revisão de conteúdos vivenciados (exemplo de roteiro pedagógico no anexo 1);

- implementação das atividades pedagógicas e organização das propriedades: a equipe técnica da Fundação Turística de Joinville (formada por bacharéis de turismo, engenheira agrônoma e pedagoga) desenvolveu os materiais de apoio sugeridos (jogos, painéis, fotos, etc) e capacitou os agricultores para sua utilização. A equipe também realizou orientações no sentido da melhor estruturação física da propriedade para o recebimento de grupos de crianças.

- realização de testes: após implementadas as atividades, a equipe da Fundação Turística de Joinville selecionou escolas municipais para realizarem os testes nas propriedades rurais. Para isso, as turmas escolhidas foram inicialmente preparadas pelas escolas e depois da visita um questionário de avaliação foi preenchido 
pelas professoras;

- adequações: de posse da avaliação dos professores, da avaliação da equipe técnica da Fundação Turística de Joinville e dos próprios agricultores, foram discutidas ações necessárias para a melhoria e consolidação do projeto. Cabe destacar que toda a estruturação do projeto foi feita de forma participativa e em grupo. No caso das adequações, por exemplo, as avaliações eram lidas, discutidas e encaminhadas em reunião com 0 conjunto dos envolvidos (técnicos e agricultores). Foram pactuados procedimentos a serem utilizados por todos os agricultores, dentre os quais: utilização de mesmo preço; utilização de formulário de reserva desenvolvido pela Fundação Turística; envio de informações sobre o grupo visitante para a Fundação Turística, com vistas a contabilização de visitas e também envio de formulário de avaliação; realização de encontro mensal do grupo de agricultores para avaliação e troca de experiências, além da discussão de novos passos necessários para o avanço do projeto;

- apoio a ações de promoção e comercialização do turismo pedagógico: esta etapa teve como objetivo a elaboração de material informativo e promocional. O material foi composto por web-site com informações detalhadas sobre o projeto (Figura 1), folder (Figura 2), DVD do projeto para ações promocionais, sinalização das propriedades com cata-vento de identificação (Figura 3) e cata-vento de papel confeccionado com mensagens relacionadas à agricultura e meio ambiente, sendo este material entregue para as crianças ao final das visitas. Realizou-se também uma ação promocional in loco em 40 instituições de ensino, locais e regionais;



Figura 1: website do projeto.

Figure 1: website of Project. 

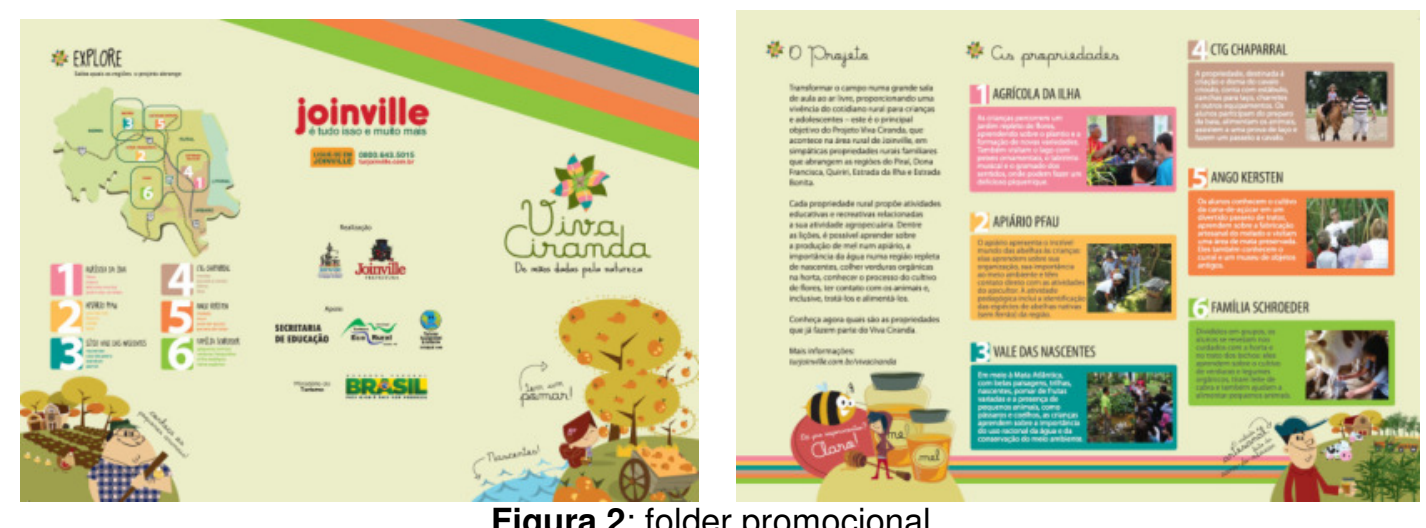

Figura 2: folder promocional.

Figure 2: promotional folder.

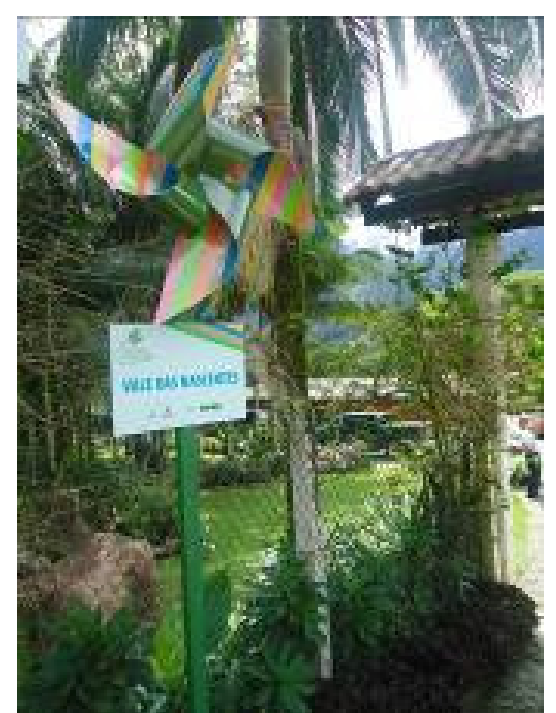

Figura 3: placa de sinalização.

Figure 3: plate of the signaling

- capacitação dos envolvidos: realização de viagem de estudos sobre turismo pedagógico em propriedades rurais na França com a participação de técnicos e seis agricultores integrantes do projeto. Ainda como etapa de capacitação, foi organizado um seminário de debates e troca de experiências sobre o processo de ensino-aprendizagem no turismo pedagógico e a realização de oficinas de formação.

\section{Resultados parciais do programa para o período}

Após 10 meses de implantação do Projeto, pode-se estabelecer os seguintes resultados:

Como etapa de estruturação das propriedades rurais, o projeto aprovado pelo Ministério do Turismo beneficiou diretamente quatro escolas municipais localizadas em bairros de menor índice de desenvolvimento humano (IDH). Foram 55 visitas, contemplando 1.650 alunos. No entanto, conforme formulários de solicitação de reservas desenvolvidos pela Fundação Turística de Joinville e aplicado pelos agricultores nos meses de maio até outubro de 2011, aconteceram 28 visitas espontâneas decorrentes da divulgação e promoção do projeto, totalizando mais 998 alunos de 13 
escolas. Desta forma, pode-se contabilizar um total de 2.648 alunos de 83 grupos pertencentes a 18 escolas do município de Joinville (média de 32 crianças por grupo).

O projeto tem beneficiado atualmente 13 propriedades, distribuídas em 5 regiões rurais (durante o ano de 2010 eram 6 propriedades ). Além das visitas, que duram em média três horas, no valor de $R \$ 5,00$ (cinco reais) por alunos/visitante, as escolas são instruídas quanto a principal produção da propriedade e o que ela oferece para venda (mel, melado, ovos, legumes, bolachas, etc.). Sendo assim, os professores divulgam através de informativos aos pais dos alunos, juntamente com o pedido de autorização para saída de campo, a possibilidade de compra dos produtos rurais. A receita financeira auferida com a venda direta de produtos tem sido, frequentemente, maior que aquela proveniente da taxa de visita.

Outro ponto de destaque tem sido a ampliação do número de visitas as propriedades rurais fora do contexto do programa de turismo pedagógico, ou seja, as crianças passam a ser as porta-vozes das propriedades e convidam seus familiares para passeios de final de semana.

Levando-se em conta apenas as receitas decorrentes da taxa de visita (cerca de $R \$ 13.240,00$ ), pode-se estimar uma receita média, por propriedade, de cerca de $\mathrm{R} \$ 2.206,67,00$ no período de 10 meses.

Dentre todos os resultados, certamente o que gerou impactos mais positivos da iniciativa foi a valorização da agricultura familiar. Em pouco mais de 10 meses de projeto, foram mais de 88 registros, 18 em rádios (46 minutos), 23 em televisão (45 minutos) e 47 em mídia impressa (12.565,00 $\mathrm{cm}^{3}$ ). Todas elas destacaram a importância da agricultura familiar na produção de alimentos; na preservação ambiental e no processo de ensinoaprendizagem. Além disso, o ponto de vista das crianças e professores sobre a profissão de agricultor também é impactado. O senso comum imperativo nas grandes cidades vê o agricultor como aquela pessoa atrasada, sem estudos. Depoimentos de crianças do tipo "agora eu já sei o que eu quero ser quando crescer: quero ser agricultor", enchem os agricultores de orgulho e coragem para continuar com o seu trabalho. Esta valorização influenciou também no envolvimento familiar, podendo perceber uma maior participação da mulher e dos filhos.

\section{Considerações Finais}

Apesar do projeto Viva Ciranda estar diretamente relacionado com o ambiente rural, e focado no desenvolvimento do turismo pedagógico nas propriedades rurais de Joinville, a atividade também pode ser caracterizada como uma prática de educação ambiental, cujo objetivo é demonstrar na prática o conteúdo apresentado em sala de aula.

No entanto, uma simples aula ao ar livre, em meio a natureza e ao campo, deve ser planejada do ponto de vista pedagógico, tornando uma experiência atrativa e lúdica, com foco na atividade principal da propriedade e possíveis de serem trabalhados em sala de aula. Esta sensibilidade no desenvolvimento da atividade, bem como a materialização das práticas através de experimentações com os proprietários, professores e alunos, têm fortalecido a atividade. Detalhes como o acompanhamento e monitoramento 
das atividades aplicadas e a assessoria técnica reforçam a necessidade destas práticas cotidianas.

Métodos avaliativos como o relato de professores, alunos e agricultores foram identificados como importante ferramenta na gestão do projeto. A motivação destes atores, principalmente das escolas participantes, refletiu também na promoção e divulgação da atividade, ainda em nível local.

Estratégias de divulgação, através do desenvolvimento de web-site, material personalizado, cartilhas descritivas com roteiro detalhado, vídeo institucional, apresentação em eventos e promoção nas principais escolas e agências de turismo especializadas na região e cidades-pólo, demonstraram que o processo de comercialização deve ser planejado e focado para a essência da atividade e para o público-alvo em questão.

O desenvolvimento de atividades curtas com agendamento prévio e a proximidade dos serviços turísticos rurais, também foram identificados como pontos fortes, favorecendo o deslocamento das turmas escolares para a área rural e possibilitando ao agricultor o tempo livre para suas práticas agropecuárias.

Apesar do turismo pedagógico em propriedades rurais ser uma atividade recente no município de Joinville, identificou-se que há uma potencialidade de replicabilidade, visto que os resultados têm-se mostrado positivos e de boa aceitação por parte da área da educação, diante a proposta pedagógica e do segmento de agroturismo, por sua estruturação, favorecimento do associativismo e motivação por parte dos envolvido.

\section{Referências bibliográficas}

ABRAMOVAY, R. Agricultura familiar e desenvolvimento territorial. São Paulo. (Mimeogr.).1998. 20 p.

BRASIL. Ministério do Turismo. Turismo rural: orientações básicas. I Ministério do Turismo, Secretaria Nacional de Políticas de Turismo, Departamento de Estruturação, Articulação e Ordenamento Turístico, Coordenação Geral de Segmentação. - 2.ed - Brasília: Ministério do Turismo, 2010.

FAO/INCRA. Perfil da agricultura familiar no Brasil: dossiê estatístico. Brasília, 1994. 24p.

IPPUJ.-Fundação Instituto de Pesquisa e Planejamento para o Desenvolvimento Sustentável de Joinville. Joinville em números, 2011.

GOODMAN, D.; SORJ, B.; WILKINSON, J. Da lavoura às biotecnologias: agricultura e indústria no sistema internacional. Rio de Janeiro: Editora Campus, 1990.

GRAZIANO da SILVA, J. A modernização dolorosa: estrutura agrária, fronteira agrícola e trabalhadores rurais no Brasil. Rio de Janeiro: Zahar, 1982.

GUERRA, P. ?Que és el consumo responsáble. In: Economia solidária Cartilha $n^{\circ}$ 3. Programa Kolping. Montevidéo, 2008. 
GUZZATTI, C.T. O agroturismo como instrumento de desenvolvimento rural: sistematização e análise das estratégias utilizadas para a implantação de um programa de agroturismo nas encostas da Serra Geral. Dissertação (Mestrado) - Programa de Pós-Graduação em Engenharia de Produção. Centro Tecnológico, Universidade Federal de Santa Catarina, Florianópolis, 2003.

GUZZATTI, C.T. O agroturismo elemento dinamizador na construção de territórios rurais: o caso da Associação de Agroturismo Acolhida na Colônia em Santa Rosa de Lima (SC). Tese (Doutorado) - Programa de PósGraduação em Geografia. Centro de Filosofia e Ciências Humanas, Universidade Federal de Santa Catarina, Florianópolis, 2010.

IBGE,- Instituto Brasileiro de Geografia e Estatística. Censo Agropecuário, 2006.

IBGE,- Instituto Brasileiro de Geografia e Estatística. Censo Demográfico, 2010.

MANCE, E.A., Revolução das Redes. Vozes, Rio de Janeiro, 1999.

MINISTÉRIO DO TURISMO. Programa de regionalização do turismo Roteiros do Brasil: Segmentos do Turismo. Brasília: Secretaria Nacional de Políticas de Turismo, 2006.

MINISTÉRIO DO TURISMO. Turismo de estudos e intercâmbio: orientações básicas. Ministério do Turismo, Secretaria Nacional de Políticas de Turismo, Departamento de Estruturação, Articulação e Ordenamento Turístico, Coordenação Geral de Segmentação. Brasília: Secretaria Nacional de Políticas de Turismo, 2008.

MINISTÉRIO DO TRABALHO E EMPREGO. Termo de Referência em Economia Solidária: Plano Nacional de Qualificação 2003-2007. Brasília: MTE/SENAES, 2005.

NAVARRO, Z. Desenvolvimento rural no Brasil: os limites do passado e os caminhos do futuro. Revista Estudos Avançados, volume 15, número 43. Instituto de Estudos avançados. USP. São Paulo, dezembro de 2001.

SINGER, P. Introdução à economia solidária. São Paulo, Fundação Perseu Abramo, 2002.

VEIGA, J.E. O desenvolvimento agrícola: uma visão histórica. São Paulo: Hucitec/USP, 1991.

VEIGA, J.E. Agricultura familiar e sustentabilidade. Cadernos de Ciência \& Tecnologia, Brasília, vol. 13, no 3; pp. 383-404.

VEIGA, J.E. Cidades imaginárias: o Brasil é menos urbano do que se calcula. Campinas, SP: Autores Associados, 2002.

VINHA, M.L. O Turismo Pedagógico e a Possibilidade de Ampliação de Olhares. Hórus - Revista Eletrônica de Humanidades e Ciências Sociais Aplicadas. Ourinhos, SP, n. 3, 2005. Disponível em: <http://www.faeso.edu.br/horus> Acessado em: 28/05/2012. 


\section{Anexo 1}

\section{Exemplo de roteiro pedagógico para propriedade produtora de mel}

Propriedade: Apiário Pfau (foco produção de mel com abelhas nativas/sem ferrão)

Faixa etária : Séries Iniciais do Ensino Fundamental (7 a 11 anos)

Enredo: de onde vem o mel que está no seu pote?

As crianças, em geral, têm pouco contato com a origem dos alimentos que consomem, desconhecendo - e, portanto, não valorizando - seus processos produtivos. A ideia dessa visita é a de mostrar às crianças o trabalho das abelhas e o trabalho humano envolvidos na fabricação do mel - e de outros produtos apícolas.

Material: favos de mel, material de cozinha para fazer um bolo/pão de mel, ingredientes do bolo, caixa de abelha de vidro, suporte para a brincadeira de abelha (favos de papelão papietado) e abelhas de brinquedo (pelúcia, fantoche de meia ou sucata, que podem ser feitas em uma oficina com crianças na escola durante a aula de artes), imagens das diferentes abelhas existentes na propriedade, plaquinhas com o nome das abelhas.

Locais: "percurso" das caixas de abelhas, agroindústria.

Roteiro:

\section{1 - RECEPÇÃO: PREPARANDO O LANCHE}

Inicialmente, a pessoa que está recebendo as crianças vai propor ao grupo de preparar um lanche bem gostoso para mais tarde: uma receita com mel. É importante que todos lavem a mão e que se escolha sempre receitas que vão ao forno. Durante a preparação da receita, é interessante conversar com as crianças sobre a origem de cada um dos ingredientes, podendo chamar à atenção, em todos eles, da necessidade das abelhas e de um ecossistema equilibrado para que continuem sendo produzidos. É interessante sempre perguntar às crianças o que elas já sabem sobre cada alimento, para depois, a partir das respostas delas, complementar, ou negar com cuidado, ou concordar. O último ingrediente a ser mencionado deve ser o mel, envolvendo as crianças quanto à possibilidade de elas verem todo 0 seu processo de fabricação. Pode-se perguntar: como vocês conhecem o mel? E o que vocês acham que acontece para que o mel chegue até vocês, dentro de uma embalagem? Nessa parte, o interesse não está tanto em explicar o processo do mel, já que as crianças vão poder vivenciá-lo a seguir, mas em deixá-las com vontade de conhecer os "segredos" do mel, que só uma apicultora ou um apicultor poderia revelar a elas.

\section{2 - QUEM FAZ O MEL? - CONHECENDO AS ABELHAS}

A organização ideal para essa parte do roteiro é que as crianças sentem em círculo, confortavelmente, junto com quem as estará recepcionando, para conversar. Em um primeiro momento, pode-se perguntar às crianças se elas já viram abelhas, onde já viram e como elas eram. A partir dessa conversa, se conversará com as crianças indagando: mas será que todas as abelhas são iguais? Se mostrará então uma das fotos ampliadas de abelha nativa e perguntará: será que essa é uma abelha? Se discutirá as respostas com as 
crianças e apresentará as abelhas, a partir das imagens, dizendo algumas características e curiosidades de cada. Se dirá a diferença da abelha nativa e da abelha africanizada, destacando que ambas dão mel, mas o mel que costumamos comer vem da segunda. Se convidará as crianças, então, para, num primeiro momento, conhecer de perto as abelhas nativas, pedindo ajuda a elas para organizar as plaquinhas do percurso.

\section{3 - O PERCURSO}

As crianças caminharão então entre as colmeias dispostas no jardim. Se pedirá a elas que observem as abelhas e, pelo que elas já aprenderam sobre cada abelha nativa, descubram qual é qual, para que se coloque ao lado da colmeia o nome da abelha. É importante que a pessoa que estará recebendo as crianças reforce as características de cada colmeia, para que essa descoberta não fique, para as crianças, no "chute".

\section{4 - A CAIXA DE VIDRO}

Se reforçará então as diferenças das abelhas nativas e das abelhas africanizadas, e se convidará as crianças para ver essa segunda, dando ênfase ao fato de que, por ter ferrão, não se pode ter contato com ela sem proteção - nessa parte, é interessante que se fale sobre um pouco da rotina do apicultor em relação às abelhas, de como se protege... Se mostrará então a caixa de vidro, explicando as diferenças com uma caixa normal que ela só é assim para que as crianças possam ver, que a saída está trancada... - e as semelhanças por dentro. Se mostrará então o que se passa dentro da caixa, que funções as abelhas exercem ali dentro.

\section{5 - ENCENANDO PARA COMPREENDER MAIS}

As crianças serão então convidadas a sentar-se de frente para a "colmeia" de papietagem e encenar o que viram dentro da caixa, no favo construído. Pode-se chamar uma criança (ou mais do que uma, dependendo do tamanho da "colmeia") para cada "tipo" de abelha existente na colmeia, e a apicultora vai dando as instruções do que cada abelha precisa fazer para que ao fim haja mel. É interessante que essas instruções estejam sempre recheadas de comentários sobre a preservação ambiental e a importância da apicultura. Quando na encenação os favos estiverem cheios de mel, a pessoa que estará recebendo as crianças poderá dizer que vai mostrar como é que fica de verdade, e pegar o favo de mel.

\section{6 - DO FAVO AO POTE}

Se perguntará às crianças, então, o que é que falta para que o mel fique como ele chega na casa delas. Se falará então do processo que acontece na agroindústria, mostrando às crianças as máquinas, as etapas e o resultado final - que poderá ser comprado pelas crianças no fim da visita.

\section{7 - AS ABELHAS PRODUZEM SÓ O MEL?}

Antes de passar ao lanche, é interessante que se fale dos outros produtos das abelhas, como o pólen e o própolis... e depois... é se deliciar com a receita preparada! 

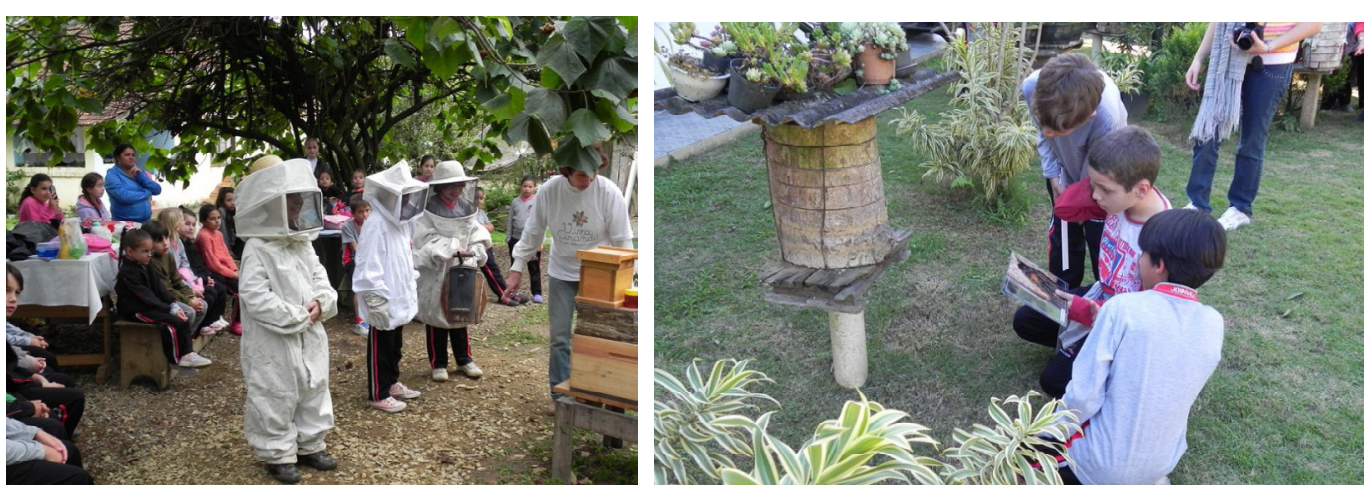

Figuras 4 e 5: alunos experimentam vestimenta e identificam as espécies de abelhas nativas.

Figures 4 and 5: Students experience clothing and identify the species of native bees.

Thaise Costa Guzzatti: Universidade Regional de Blumenau, Blumenau, SC, Brasil.

E-Mail: thaise.acolhida@gmail.com

Link para o currículo Lattes: http://lattes.cnpq.br/3969366822285939

Vinicius Boneli Vieira: Fundação Turística de Joinville, Joinville, SC, Brasil. E-Mail: vinicius@turjoinville.com.br Link para o currículo Lattes: http://lattes.cnpq.br/0246902049266303

Vanessa Cristina Venzke Falk: Fundação Turística de Joinville, Joinville, SC, Brasil.

E-Mail:vanessa@turjoinville.com.br

Link para o currículo Lattes: http://lattes.cnpq.br/4726217245542212

Valério Alécio Turnes: Universidade do Estado de Santa Catarina, Florianópolis, SC, Brasil.

E-Mail: valerio.turnes@yahoo.com.br

Link para o currículo Lattes: http://lattes.cnpq.br/2685253495482236

Data de submissão: 20 de junho de 2012

Data de recebimento de correções: 11 de junho de 2013

Data do aceite: 11 de junho de 2013

Avaliado anonimamente 